\title{
EVIDENCE FOR THE INVOLVEMENT OF PURINERGIC SIGNALLING IN THE CONTROL OF RESPIRATION
}

\author{
T. THOMAS, ${ }^{\mathrm{b}, 1 *}$ V. RALEVIC, ${ }^{\mathrm{c}, 1}$ M. BARDINI, ${ }^{\mathrm{a}}$ G. BURNSTOCK ${ }^{\mathrm{a}}$ and K. M. SPYER ${ }^{\mathrm{a}}$ \\ ${ }^{a}$ Autonomic Neuroscience Institute, Royal Free and University College Medical School, Royal Free Campus, \\ Rowland Hill Street, London NW3 2PF, UK \\ ${ }^{\mathrm{b}}$ Department of Physiology, Division of Medical Sciences, University of Birmingham, Vincent Drive, Birmingham B15 2TT, UK \\ ${ }^{\mathrm{c}}$ School of Biomedical Sciences, The University of Nottingham, Queens Medical Centre, Nottingham NG7 2UH, UK
}

\begin{abstract}
The ventrolateral medulla has a critical role in the generation and patterning of respiration via an extensive network of respiratory neurones. We have investigated the effects of activating purinergic $\mathrm{P} 2$ receptors within the ventrolateral medulla of the anaesthetised rat on the overall pattern of respiratory activity. In addition, using immunohistochemical techniques, we have identified the subtypes of $\mathrm{P} 2 \mathrm{X}$ receptors in the ventrolateral medulla. Unilateral microinjection of ATP into the ventrolateral medulla reduced in a dose-dependent manner, or abolished, resting phrenic nerve discharge recorded as an indication of central inspiratory drive. ATP also elicited increases in blood pressure and variable changes in heart rate. These effects were mimicked by microinjection of the P2X receptor agonist $\alpha, \beta$-methylene ATP into the ventrolateral medulla. Whilst microinjection of suramin, a P2 receptor antagonist, had no effect on resting cardiorespiratory variables it blocked the respiratory and cardiovascular effects of ATP microinjected into the ventrolateral medulla. Immunohistochemical staining using $\mathrm{IgG}$ antibodies showed that $\mathrm{P} 2 \mathrm{X}_{1}, \mathrm{P} 2 \mathrm{X}_{2}, \mathrm{P} 2 \mathrm{X}_{5}$ and $\mathrm{P} 2 \mathrm{X}_{6}$, but not $\mathrm{P} 2 \mathrm{X}_{3}, \mathrm{P} 2 \mathrm{X}_{4}$ or receptor subunits were localised in the rostral ventrolateral medulla.

Our results indicate that several $\mathrm{P} 2 \mathrm{X}$ receptor subtypes are localised within areas of the ventrolateral medulla that are important for cardiorespiratory control (including the pre-Bötzinger and Bötzinger complexes), and that activation of these receptors can have profound effects on both the cardiovascular and the respiratory networks. Our pharmacological data suggest that different P2X subunits in this region may co-assemble to form hetero-oligomeric assemblies as well as homomultimers within this region. (C) 2001 IBRO. Published by Elsevier Science Ltd. All rights reserved.
\end{abstract}

Key words: ATP, P2 receptors, immunohistochemistry, ventrolateral medulla, brainstem, breathing.

$\mathrm{ATP}$, acting via $\mathrm{P} 2 \mathrm{X}$ ion channel receptors, is a fast neurotransmitter within the CNS (Jahr and Jessel, 1983; Edwards et al., 1992; Day et al., 1993; Torres et al., 1999). In recent years, there has been a growing body of evidence that ATP acting at P2X receptors within the medulla oblongata can modulate cardiovascular activity (Phillis et al., 1997; Horiuchi et al., 1999; Ralevic et al., 1999). In particular, we have shown that ATP applied iontophoretically to presumptive vasomotor neurones within the ventrolateral medulla (VLM) evokes a potent excitatory effect (Ralevic et al., 1999). This may explain why activation of $\mathrm{P} 2 \mathrm{X}$ receptors in VLM evokes a large increase in arterial pressure, accompanied by a significant increase in sympathetic nerve activity (Sun et al., 1992; Horiuchi et al., 1999).

\footnotetext{
1 Joint senior author.

*Corresponding author. Tel.: +44-121-414-6938; fax: +44-121-4146919.

E-mail address: t.j.thomas@bham.ac.uk (T. Thomas).

Abbreviations: $\alpha, \beta$-meATP, $\alpha, \beta$-methylene ATP; ABP, arterial blood pressure; HR, heart rate; NHS, normal horse serum; PBS, phosphate-buffered saline; VLM, ventrolateral medulla.
}

However, this area of the VLM also contains an extensive respiratory network, including the pre-Bötzinger and Bötzinger complexes and the nucleus ambiguus (Richter, 1996). This 'ventral respiratory group' has a fundamental role in controlling the activity of the respiratory muscles. Whilst it is clear that ATP can act on the cardiovascular neurones in this area, the possibility that ATP might also modulate respiratory activity within the VLM has not been fully addressed. However, this prospect seems likely since we have recently illustrated that $\mathrm{P} 2 \mathrm{X}$ receptors within the VLM are an important component in carbon dioxide-mediated changes in respiration (Thomas and Spyer, 2000).

In this study we have addressed the question of whether ATP receptors within the VLM are involved in respiratory control. First, we have investigated the effects of microinjection of ATP and its stable analogue $\alpha, \beta$-methylene ATP $(\alpha, \beta$-meATP) into the pre-Bötzinger and Bötzinger complexes on both cardiovascular and respiratory activity simultaneously. In addition, we have employed immunohistochemical techniques in order to visualise, and localise, the P2X receptor subtypes present within the VLM.

Some of these results have been reported previously in preliminary abstracts (Ralevic et al., 1998; Thomas et al., 2000). 


\section{EXPERIMENTAL PROCEDURES}

\section{In vivo studies}

General methods. All studies were carried out on male Sprague-Dawley rats supplied by the Royal Free and University College Medical School, London, UK (275-320 g) anaesthetised initially with pentobarbital sodium (Sagatal May\&Baker, UK, $60 \mathrm{mg} / \mathrm{kg}$, i.p.), with anaesthesia being maintained with supplemental doses as required $(10 \mathrm{mg} / \mathrm{kg}$, i.v.). The depth of anaesthesia was assessed by monitoring the stability of arterial blood pressure (ABP), heart rate (HR) and phrenic nerve discharge (see below), and the minimal effects on cardiovascular variables of a pinch to the paw. All of the following procedures and protocols were carried out in accordance with the UK Animals (Scientific Procedures) Act, 1986. All efforts were made to minimise animal suffering and to use only the number of animals necessary to produce reliable scientific data.

The femoral artery and vein were cannulated for measurement of ABP and administration of supplemental anaesthetic respectively. A cannula was placed into the trachea, and the animal ventilated artificially with oxygen-enriched air (Harvard ventilator, model 683). The animal was then paralysed with gallamine triethiodide (Flaxedil ${ }^{\mathbb{T}}$, $10 \mathrm{mg} / \mathrm{kg}$, then $\left.1-2 \mathrm{mg} / \mathrm{kg} / \mathrm{h}, \mathrm{i} . \mathrm{v}.\right)$. The animal was placed in a stereotaxic frame and an occipital craniotomy performed. The cerebellum was partially removed to expose the dorsal surface of the lower brainstem. The activity of the phrenic nerve was recorded as an indication of central respiratory drive. The nerve was dissected, cut peripherally and prepared for recording. The signal was amplified $(\times 10000)$, filtered $(500-1500 \mathrm{~Hz})$ and rectified and smoothed $(\tau=100$ $\mathrm{ms}$ ); (Neurolog system, Cambridge Electronic Design, Cambridge, UK). Arterial blood samples were taken to ensure levels of oxygen, carbon dioxide and $\mathrm{pH}$ were kept within physiological levels $\left(\mathrm{PaO}_{2}, 90-100 \mathrm{~mm} \mathrm{Hg} ; \mathrm{PaCO}_{2}, 35-45 \mathrm{~mm} \mathrm{Hg} ; \mathrm{pH}\right.$, 7.35-7.4; Corning Blood Gas Analyser (Model 158), Corning, UK). A five-barrelled micropipette, prepared for microinjection (tip size 40-60 $\mu \mathrm{m}$ ) was placed in the VLM using stereotaxic coordinates: $2.3 \mathrm{~mm}$ rostral to obex, $2 \mathrm{~mm}$ lateral to midline and 2.8-3 mm ventral from the surface (Paxinos and Watson, 1998).

Protocol. Unilateral microinjections $(50 \mathrm{nl})$ of glutamate (0.2 M, pH 7.4) were made into the right or left VLM using pressure. The injection of drug was monitored using a dissecting microscope with a calibrated micrometre disk and made over $5 \mathrm{~s}$. If a brisk cardiorespiratory response was observed upon injection of glutamate, a control response to the injection of ATP $(2 \mathrm{mM}, \mathrm{pH} 7.4,50 \mathrm{nl})$ into the same site was obtained. Once levels of cardiovascular and respiratory variables had returned to baseline, a higher dose of ATP $(20 \mathrm{mM}, \mathrm{pH} 7.4,50 \mathrm{nl})$ was microinjected into the same site. Once levels of cardiovascular and respiratory variables had again returned to baseline the P2 receptor antagonist suramin $(0.02 \mathrm{M}, \mathrm{pH} 7.4,50 \mathrm{nl})$ was microinjected into the same site. After $5 \mathrm{~min}$, the lowest dose of ATP was again microinjected into this site. Once stable baselines had resumed, the higher dose of ATP was again tested at the same site.

In a different group of animals the $\mathrm{P} 2 \mathrm{X}$ agonist $\alpha, \beta$-meATP $(0.2-2 \mathrm{mM}, \mathrm{pH} 7.4,50 \mathrm{nl})$ was microinjected into the left or right VLM. Since this compound is known to cause receptor desensitisation, in some cases we repeated the microinjection of $\alpha, \beta$-meATP into the same site after all variables had returned to baseline levels and not less than $10 \mathrm{~min}$ had elapsed since the previous injection. The sites of microinjection were marked by pressure injection of Pontamine Sky Blue dye.

We have shown previously that vehicle injections into this area of the brainstem are ineffective (Thomas and Spyer, 1996).

Histology. At the end of each experiment the brain was removed, fixed in $10 \%$ formal saline, frozen, sectioned serially $(100 \mu \mathrm{m})$ and counterstained with Neutral Red. Microinjections were visualised using a light microscope and mapped using a stereotaxic atlas (Paxinos and Watson, 1998).
Data recording and analysis. Records of ABP, neuronal activity, phrenic nerve activity and integrated phrenic nerve activity were stored on computer and analysed using Spike 2 software (Cambridge Electronic Design). HR was calculated off-line from the blood pressure recording. Levels of mean ABP, $\mathrm{HR}$ and frequency of phrenic nerve discharge were measured immediately before microinjection of ATP or $\alpha, \beta$-meATP and compared to the maximum response during drug application. The responses before and after suramin were compared using analysis of variance (ANOVA) with post-hoc Bonferroni's test for multiple comparisons. All data are presented as mean \pm S.E.M. In all instances $P<0.05$ was considered statistically significant.

Drugs. ATP (disodium salt), L-glutamate, $\alpha, \beta$-meATP (lithium salt) and Pontamine Sky Blue were purchased from Sigma (Poole, UK). Suramin was from Bayer. Pontamine Sky Blue was dissolved in $0.2 \mathrm{M}$ sodium acetate. All other drugs were dissolved in $1 \mathrm{mM}$ saline. $\mathrm{pH}$ was adjusted by adding $0.5 \mathrm{M}$ $\mathrm{NaOH}$ or $0.5 \mathrm{M} \mathrm{HCl}$. Purine compounds were used at concentrations used by others and us previously (Sun et al., 1992; Ralevic et al., 1998)

\section{Immunohistochemical studies}

Tissues. Male rats (275-320 g) were killed by an overdose of pentobarbital sodium given i.p. The brainstem was removed and immersion-fixed overnight at $4{ }^{\circ} \mathrm{C}$ in $4 \%$ paraformaldehyde containing $0.2 \%$ of a saturated solution of picric acid in $0.1 \mathrm{M}$ phosphate buffer. The tissues were washed in $7 \%$ sucrose and left overnight in this solution at $4^{\circ} \mathrm{C}$.

The tissues were then embedded in OCT compound (BDH/ Merck, Leicestershire, UK) and frozen in isopentane pre-cooled in liquid nitrogen. Consecutive sections of $10 \mu \mathrm{m}$ were taken using a cryostat (Reichert Jung CM1800), collected on gelatincoated slides and air-dried at room temperature. The slides were stored at $-20^{\circ} \mathrm{C}$ and allowed to return to room temperature for at least $10 \mathrm{~min}$ prior to use. One in 10 sections was taken as an overview and stained with Cresyl Violet according to the atlas of Paxinos and Watson (1998).

Development of primary antibodies. The immunogens used were peptides corresponding to 15 receptor type-specific amino acids in the $\mathrm{C}$-terminal region of the receptor. The peptide sequences are as follows: $\mathrm{P}_{2} \mathrm{X}_{1}$, amino acids 385-399

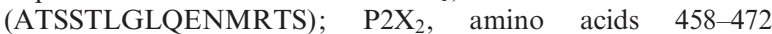

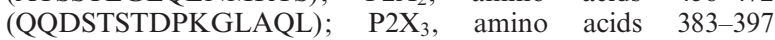
(VEKQSTDSGAYSIGH); $\mathrm{P}_{2} \mathrm{X}_{4}$, amino acids 374-388 (YVE-

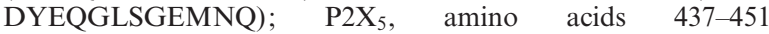
(RENAIVNVKQSQILH); $\mathrm{P}_{2} \mathrm{X}_{6}$, amino acids 357-371 (EAGFYWRTKYEEARA). The synthetic peptides were covalently linked to keyhole limpet haemocyanin and the conjugate was administered to rabbits at monthly intervals (performed by Research Genetics, Huntsville, AL, USA).

Immunoglobulin $\mathrm{G}$ ( $\mathrm{IgG})$ fractions were isolated from the immune and preimmune sera $\left(\mathrm{P} 2 \mathrm{X}_{1-7}\right)$ following the method of Harboe and Ingild (1973). The protein concentration was determined at $280 \mathrm{~nm}$ using an extinction factor of 1.43 for $1 \mathrm{mg} / \mathrm{ml}$. The specificity of the antibodies was verified by immunoblotting with membrane preparations from CHO-K1 cells expressing the cloned $\mathrm{P} 2 \mathrm{X}_{1-7}$ receptors. Immunoblotting studies have shown that anti-P $2 \mathrm{X}_{1-7}$ antibodies specifically recognise the recombinant receptors expressed in CHO-K1 cells (Oglesby et al., 1999). Pre-absorption of the antibodies with excess of the appropriate synthetic peptide used for generation of the antibodies eliminated immunoreactivity.

Immunohistochemistry. The avidin-biotin-peroxidase complex technique was employed according to the protocol described previously (Llewellyn-Smith et al., 1992, 1993). The slide-mounted sections were rinsed in phosphate-buffered saline (PBS) to remove any OCT compound. To inactivate endogenous peroxidase, the sections were then treated with $20 \%$ meth- 
anol containing $0.4 \%$ hydrogen peroxide in PBS for $10 \mathrm{~min}$ Non-specific binding sites were blocked by a 20 -min incubation with 10\% normal horse serum (NHS) in PBS containing 0.05\% merthiolate. The P2X antibodies were diluted to $5 \mu \mathrm{g} / \mathrm{ml}$ (determined as optimal by prior titration) with $10 \%$ NHS containing $0.2 \%$ Triton $\mathrm{X}-100$, and the sections were incubated with the primary antibodies overnight at room temperature. The secondary antibody was a biotinylated donkey anti-rabbit IgG (Jackson Immunoresearch, Luton, UK) used at a dilution of 1:500 for $1 \mathrm{~h}$, followed by the ExtrAvidin peroxidase conjugate (Sigma, St. Louis, MO, USA) at 1:1500 for $1 \mathrm{~h}$.

To visualise the reaction product, the nickel-diaminobenzidine enhancement technique was used. The specimens were dehydrated to xylene and mounted in Eukitt (BDH/Merck, Leicestershire, UK). Controls were performed with pre-immune IgG and with the P2X antibodies pre-absorbed with the homologous peptides; no staining was observed. The results were documented using the Edge R400 high-definition light microscope (Edge Scientific Instruments, Santa Monica, CA, USA) and Kodak TMX 100 film.

\section{RESULTS}

\section{Microinjection studies}

Baseline levels of ABP, HR and frequency of phrenic nerve bursts were $117 \pm 4 \mathrm{~mm} \mathrm{Hg}, 339 \pm 11$ beats/min and $68 \pm 4$ bursts/min respectively $(n=18)$. Microinjection of glutamate $(0.2 \mathrm{M})$ into the VLM evoked a short-lasting increase in ABP $(27 \pm 6 \mathrm{~mm} \mathrm{Hg}, P<0.05)$ and a reduction, or cessation, of phrenic nerve discharge $(-86 \pm 8 \%, P<0.01)(n=18)$. Glutamate evoked inconsistent effects on HR. These responses to glutamate injection indicated that the observed effects of stimulation in this region were a result of excitation of perikarya but not fibres of passage (Fries and Zieglgansberger, 1974).

Microinjection of the low dose of ATP $(2 \mathrm{mM})$ into the same sites evoked an increase in $\mathrm{ABP}(n=6$, Table 1 and Fig. 1). ATP had variable effects on HR evoking tachycardia in four cases and bradycardia in two cases ( $n=6$, Table 1 and Fig. 1). In addition, ATP produced a marked reduction in, or abolished, phrenic nerve activity ( $n=6$, Table 1 and Fig. 1). In four of six cases, subsequent microinjection of the larger dose of ATP $(20 \mathrm{mM})$ into the same site evoked a larger increase in ABP. There were still variable changes in $\mathrm{HR}$ in response to the higher dose of ATP (Fig. 1 and Table 1).

Microinjection of the $\mathrm{P} 2 \mathrm{X}$ receptor agonist $\alpha, \beta$ meATP $(0.2-2 \mathrm{mM})$ into the VLM produced qualitatively similar effects to ATP $(n=11)$. The lowest dose of $\alpha, \beta$-meATP $(0.2 \mathrm{mM})$ evoked an increase in ABP, a tachycardia and a fall in phrenic nerve discharge which resulted in apnoea in six cases (see Table 2 and Fig. 2). Upon subsequent microinjection of a higher dose of $\alpha, \beta$ - a

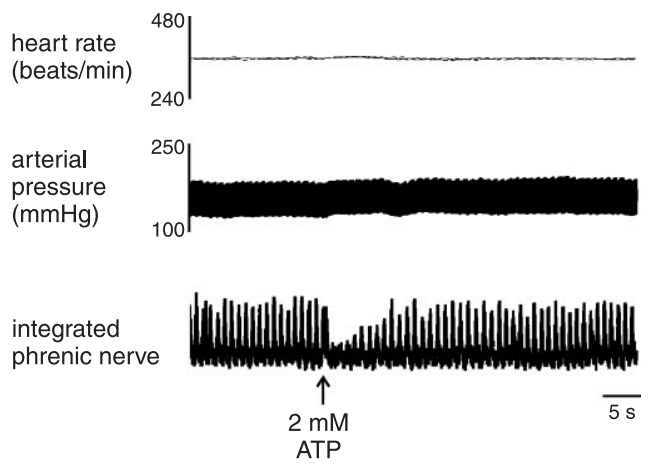

b
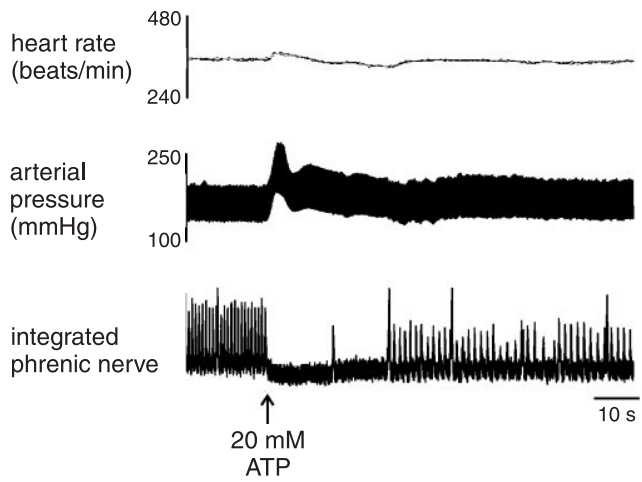

Fig. 1. Effects of activating P2 receptors in the VLM on the respiratory and cardiovascular systems. (a) Raw data taken from an individual animal illustrating the effect of microinjection (indicated by arrow) of ATP $(2 \mathrm{mM}, 50 \mathrm{nl})$ on HR, ABP and integrated phrenic nerve activity (an indication of central respiratory drive) (b) Subsequent microinjection of a higher dose of ATP $(20 \mathrm{mM}$, $50 \mathrm{nl}$ ) evoked larger cardiorespiratory responses.

meATP $(1.25 \mathrm{mM})$ into the same site, a larger cardiorespiratory response was only seen in three of nine cases. In the remaining six cases, a smaller increase in $\mathrm{ABP}$ was observed illustrating desensitisation of this component of the response to $\alpha, \beta$-meATP (Table 2 and Fig. 2). The effects on HR and phrenic frequency were no different to those evoked by the lower dose. The changes in ABP, HR and phrenic activity evoked by $\alpha, \beta$-meATP were further reduced in four of six cases upon subsequent microinjection of a third, higher, dose $(2 \mathrm{mM}$; see Table 2 for mean responses).

Microinjection of the $\mathrm{P} 2$ receptor antagonist suramin $(0.02 \mathrm{M}, n=6)$ had no significant effect on baseline levels of $\operatorname{ABP}(101 \pm 10$ vs. $113 \pm 13 \mathrm{~mm} \mathrm{Hg}), \mathrm{HR}(346 \pm 17$ vs. $354 \pm 16$ beats $/ \mathrm{min})$ and phrenic nerve activity $(82 \pm 10$ vs. $86 \pm 4$ bursts/min). The cardiorespiratory responses

Table 1. Cardiovascular and respiratory responses to microinjection of ATP into the VLM

\begin{tabular}{lll}
\hline & 2 mM ATP $(n=6)$ & $20 \mathrm{mM} \mathrm{ATP}(n=6)$ \\
\hline$\%$ change in ABP (mm Hg) & $11 \pm 2^{* *}$ & $27 \pm 7^{*}$ \\
$\%$ change in HR (beats/min) & $-3 \pm 4$ & $9 \pm 6$ \\
$\%$ change in respiratory frequency (phrenic bursts/min) & $-63 \pm 20^{*}$ & $-64 \pm 18^{* *}$ \\
\hline
\end{tabular}

${ }^{*} P<0.05,{ }^{*} P<0.01$, significant difference from baseline levels. 

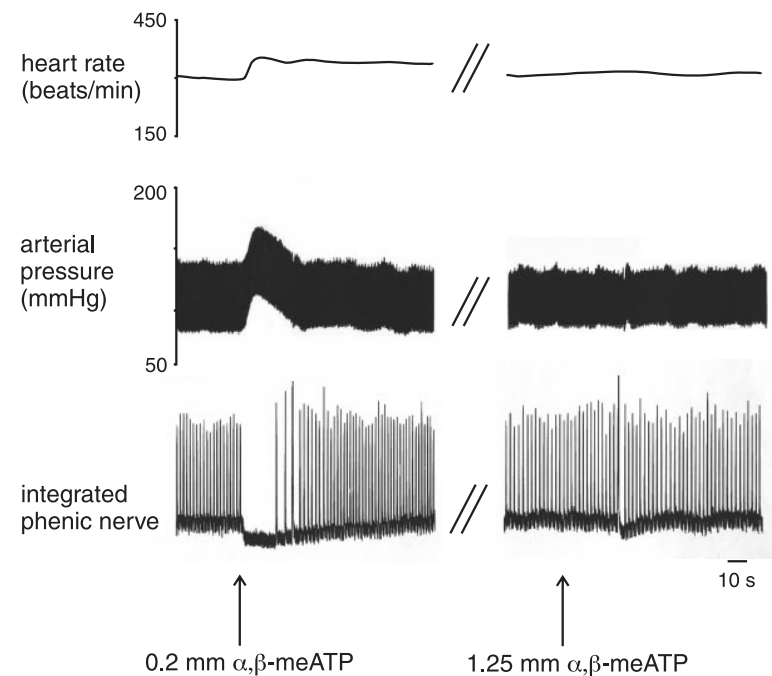

Fig. 2. Cardiorespiratory responses evoked by activation of $\mathrm{P} 2 \mathrm{X}$ receptors in the VLM showed desensitisation upon repeated microinjections of $\alpha, \beta$-meATP. Raw data from an individual animal illustrating that microinjection of the P2X receptor agonist $\alpha, \beta$ meATP $(0.2 \mathrm{mM}, 50 \mathrm{nl}$, indicated by arrow $)$ evoked an increase in $\mathrm{ABP}$ and HR and an inhibition of central respiratory drive (see Table 2). In this case a second injection of a larger dose of $\alpha, \beta$ meATP $(1.25 \mathrm{mM})$ did not evoke changes in the cardiovascular or respiratory variables, indicating desensitisation of the responses. evoked by glutamate microinjection were also unaffected by suramin (Fig. 3). However, suramin blocked the inhibitory effects of both the low and high doses of ATP on phrenic nerve activity $(P<0.05, n=6$, Fig. 3$)$. The mean increases in ABP and changes in HR evoked by low doses of ATP were also reduced by suramin at this dose (Fig. 3). Since $\alpha, \beta$-meATP caused desensitisation of the evoked responses, we were unable to investigate the effects of suramin on those responses. Histological analysis indicated our microinjections were made within the VLM in the pre-Bötzinger and Bötzinger complexes (Fig. 4).

\section{Immunohistochemical studies}

Immunohistochemistry was carried out using $\mathrm{P} 2 \mathrm{X}_{1-6}$ antibodies. Reactivity within the rostral VLM was seen with $\mathrm{P} 2 \mathrm{X}_{1}, \mathrm{P} 2 \mathrm{X}_{2}, \mathrm{P} 2 \mathrm{X}_{5}$ and $\mathrm{P} 2 \mathrm{X}_{6}$. On the other hand, there was no reaction in the rostral VLM with the other $\mathrm{P} 2 \mathrm{X}$ receptor subtypes, i.e. $\mathrm{P} 2 \mathrm{X}_{3}$ and $\mathrm{P} 2 \mathrm{X}_{4}$. However, we did observe $\mathrm{P} 2 \mathrm{X}_{3}$ and $\mathrm{P} 2 \mathrm{X}_{4}$ reactivity in more caudal and medial regions of the ventral medulla, in the lateral paragiganticellular nucleus (Paxinos and Watson, 1998).

$\mathrm{P} 2 \mathrm{X}_{1}$ immunoreactivity was present within the VLM but did not extend extensively in a rostro-caudal aspect. It was contained at a level $3.30-3.72 \mathrm{~mm}$ caudal to the interaural line. This region overlaps the so-called preBötzinger complex (Paxinos and Watson, 1998). The

a
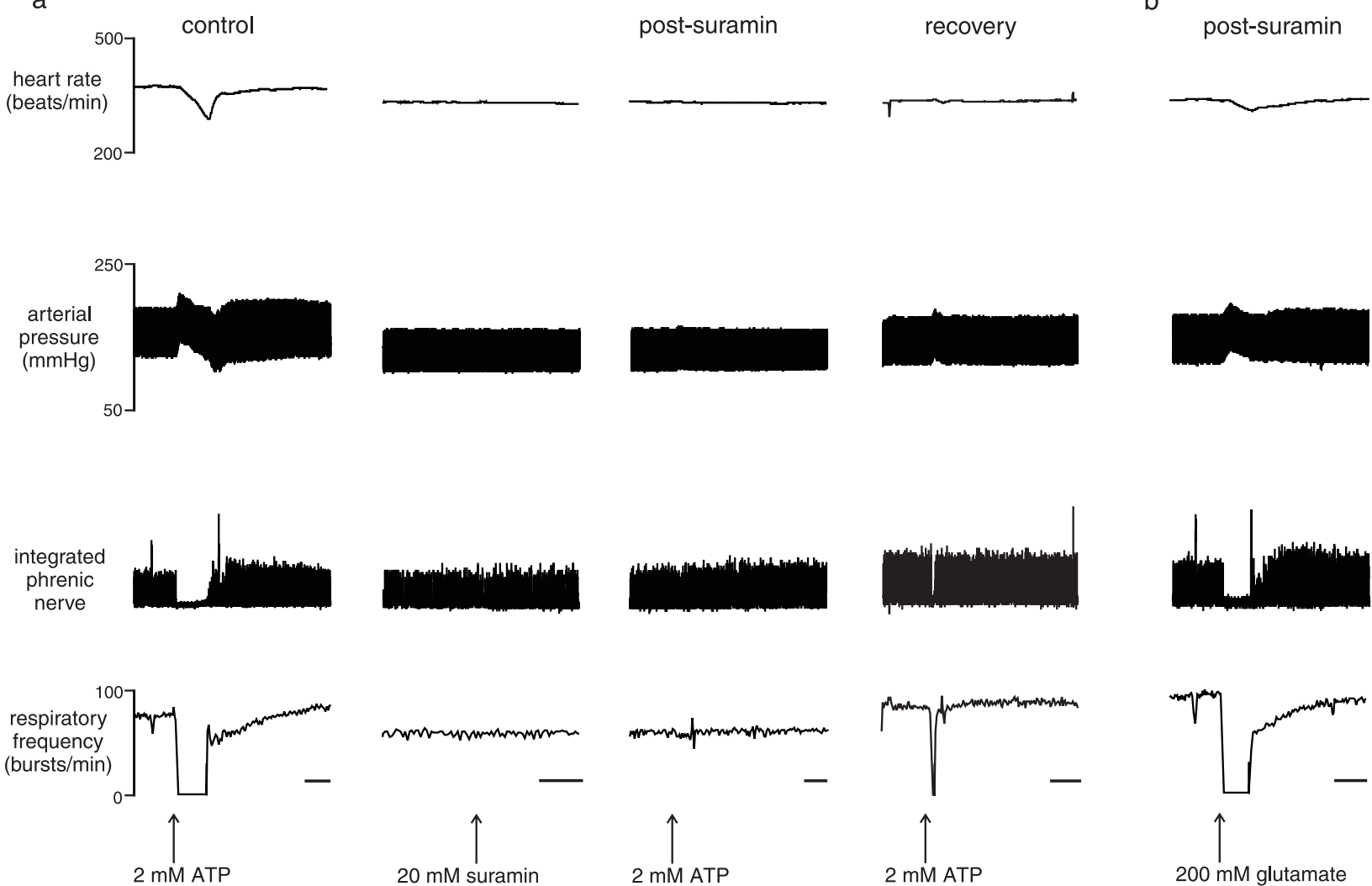

Fig. 3. Effects of the P2 receptor antagonist suramin on the responses evoked by microinjection of ATP into VLM (a) Microinjection of suramin into the ventral medulla 2 min prior to ATP microinjection into the same site reduced the inhibitory effects of ATP on respiration (see Results). In this experiment the increases in ABP and HR evoked by ATP were also abolished. In this instance the responses to ATP showed some recovery after suramin. (b) The responses evoked by microinjection of glutamate were unaffected by suramin. 


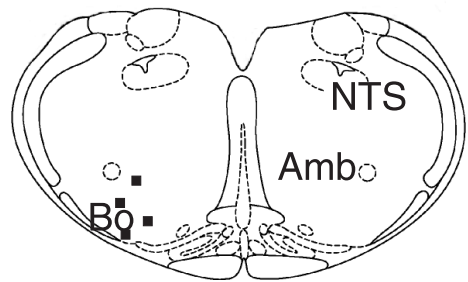

$-11.80 \mathrm{~mm}$

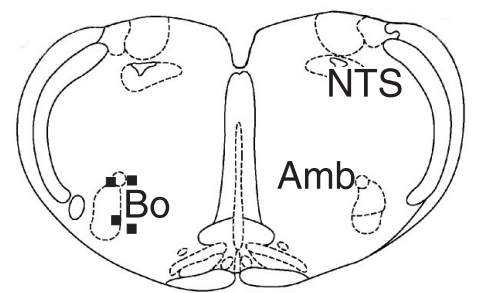

\section{$-11.96 \mathrm{~mm}$}

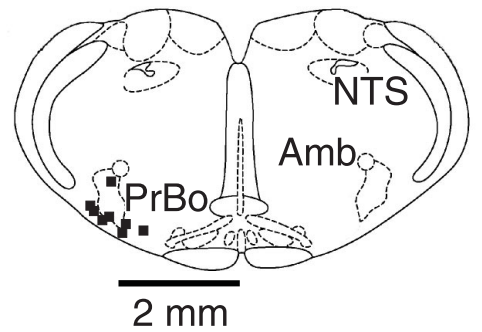

\section{$-12.30 \mathrm{~mm}$}

Fig. 4. Distribution of histologically determined sites at which microinjections were made in the VLM (see Histology section for details). Note that microinjections and recordings were not restricted to one particular side of the brainstem as illustrated here for clarity. Distances are from bregma (Paxinos and Watson, 1998). NTS, nucleus tractus solitarius; Amb, nucleus ambiguus; Bo, Bötzinger complex; PrBo, Pre-Bötzinger complex.

cell bodies showed varying degrees of immunoreactivity but reactivity was particularly strong in the smaller cells localised towards the ventral surface of the medulla (see Fig. 5A).

$\mathrm{P} 2 \mathrm{X}_{2}$ immunohistochemistry was observed in the larger cells in more dorsal regions of the rostral VLM around the nucleus ambiguus (Fig. 5). There was still, however, some immunoreactivity at the ventral surface of the medulla.

There was a strong immunoreaction to $\mathrm{P} 2 \mathrm{X}_{6}$ antibodies within the VLM (Fig. 6) and the reactivity extended from very caudal regions of the ventral medulla (3.72 $\mathrm{mm}$ caudal of the interaural line) rostrally to the retrofacial nucleus, which overlaps the Bötzinger complex (Paxinos and Watson, 1998). At very caudal levels, $\mathrm{P} 2 \mathrm{X}_{6}$ reactivity was also observed medially in the lateral paragiganticellular nucleus. In the rostral VLM there was strong $\mathrm{P}_{2} \mathrm{X}_{6}$ reactivity in the large cells of the retro- facial nucleus ( $2.80 \mathrm{~mm}$ caudal to interaural line). Short cell processes also showed immunoreaction (Fig. 6) and again, the strongest reaction was in small neurones close to the ventral surface of the section (Fig. 6). Immunoreaction was also observed in the area of the nucleus ambiguus (Fig. 6).

$\mathrm{P} 2 \mathrm{X}_{1}, \mathrm{P} 2 \mathrm{X}_{2}$ and $\mathrm{P} 2 \mathrm{X}_{6}$ antibodies pre-absorbed with an excess of the corresponding conjugated peptide used for immunisation lost all reactivity (e.g. Fig. 5F).

\section{DISCUSSION}

These studies confirm the presence of P2X purinoceptors in the VLM of the rat and indicate that activation of these receptors has a profound effect on respiratory activity. In addition to the pronounced effects on respiration, microinjection of ATP and $\alpha, \beta$-meATP elicited an increase in both $\mathrm{ABP}$ and $\mathrm{HR}$ as reported previously (Sun et al., 1992; Ralevic et al., 1998; Horiuchi et al., 1999). It is possible that our microinjections may have affected the neurones of the external formation of the nucleus ambiguus, which contains vagal parasympathetic preganglionic neurones. The $\mathrm{P}_{2} \mathrm{X}_{6}$ immunoreactivity in the nucleus ambiguus might therefore explain some of the variability of the HR responses induced by ATP. A recent study in the rabbit showed that the pressor effects of $\alpha, \beta$-meATP are accompanied by a significant increase in sympathetic nerve activity (Horiuchi et al., 1999). This is in accordance with our observation that ATP excites presumptive vasomotor neurones within the ventral medulla of the rat (Ralevic et al., 1999). However, in this study we have additionally recorded phrenic nerve activity as an indication of central respiratory drive. Microinjections of ATP and $\alpha, \beta$-meATP both produced a fall in ventilatory drive, which at higher doses resulted in expiratory apnoea. Histological analysis revealed that our microinjections were concentrated within the Bötzinger and pre-Bötzinger complexes. Studies in the rat have shown that there are predominantly expiratory neurones in the Bötzinger complex $(80 \%)$ and that at least more than half of the neurones in the pre-Bötzinger complex are expiratory or of the phase spanning IE (inspiratory off-switch) type (Sun et al., 1998). Our previous electrophysiological data indicate that whilst ATP causes a generalised excitation of respiratory neurones within the VLM, irrespective of neuronal type and whether they are associated with driving inspiration or expiration, ATP was more effective in increasing activity in post-inspiratory and expiratory neurones than inspiratory neurones (Thomas and Spyer, 2000). This obser-

Table 2. Cardiovascular and respiratory responses to microinjection of $\alpha, \beta$-meATP into the VLM

\begin{tabular}{llll}
\hline & $0.2 \mathrm{mM} \alpha, \beta-\operatorname{meATP}(n=11)$ & $1.25 \mathrm{mM} \alpha, \beta-\operatorname{meATP}(n=9)$ & $2 \mathrm{mM} \alpha, \beta-\mathrm{meATP}(n=6)$ \\
\hline \% change in ABP (mm Hg) & $15 \pm 4^{* *}$ & $7 \pm 2^{*+}$ & $6 \pm 7$ \\
$\%$ change in HR (beats/min) & $4 \pm 2^{*}$ & $4 \pm 2^{*}$ & $3 \pm 1$ \\
$\%$ change in respiratory frequency (phrenic & $-66 \pm 14^{* * *}$ & $-57 \pm 15^{* *}$ & $-22 \pm 16$ \\
bursts/min) & & &
\end{tabular}

${ }^{*} P<0.05,{ }^{* *} P<0.01,{ }^{* * *} P<0.001$, significant difference from baseline levels; ${ }^{+} P<0.05$, significant different between middle and lower dose of $\alpha, \beta$-meATP. 


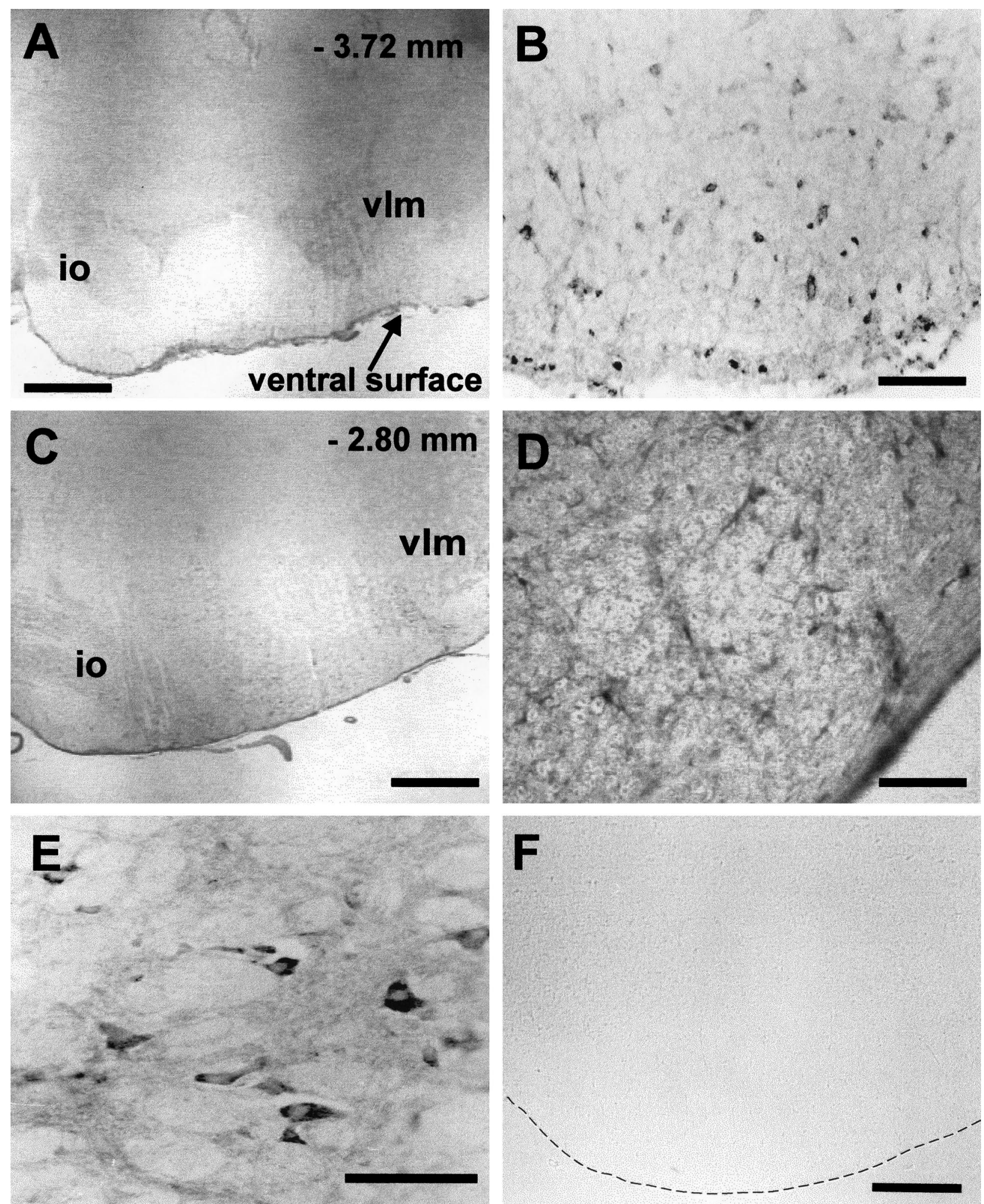

Fig. 5. $\mathrm{P} 2 \mathrm{X}_{1}$ and $\mathrm{P} 2 \mathrm{X}_{2}$ immunoreactivity in the VLM of rat. (A and $\mathrm{B}$ ) Photomicrographs of $\mathrm{P} 2 \mathrm{X}_{1}$ immunoreactivity in the VLM. P2X $\mathrm{X}_{1}$ reactivity was present in the VLM around the level of the pre-Bötzinger complex, with particularly dense staining in cells localised towards the ventral surface of the medulla. (C-E) P2X 2 immunoreactivity in the VLM. (F) Immunoreaction was abolished after absorption of a-P2X $\mathrm{X}_{6}$ with $\mathrm{P} 2 \mathrm{X}_{6}$ peptide. Dashed line represents ventral surface of medulla Scale bars $=500 \mu \mathrm{m}$ in A, C and F, $100 \mu \mathrm{m}$ in B and D, $50 \mu \mathrm{m}$ in E. Distances indicated are from bregma (Paxinos and Watson, 1988). io, inferior olive. 

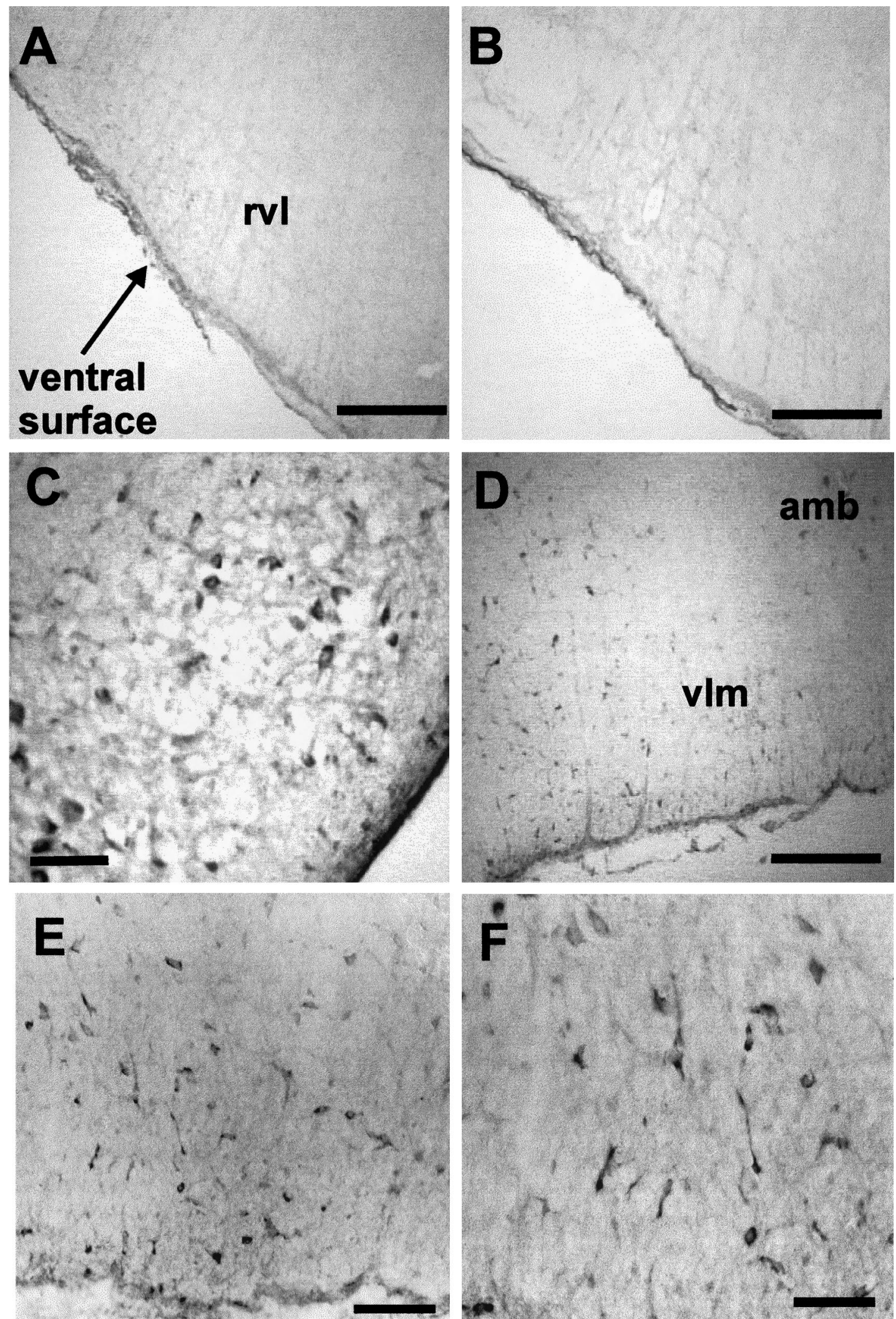

Fig. 6. $\mathrm{P} 2 \mathrm{X}_{5}$ and $\mathrm{P} 2 \mathrm{X}_{6}$ immunoreactivity in the VLM of rat. (A and $\mathrm{B}$ ) Photomicrographs indicating absence of $\mathrm{P} 2 \mathrm{X}_{3}$ and $\mathrm{P}_{2} \mathrm{X}_{4}$ immunoreactivity in rostral regions of the VLM (rvl, rostral ventrolateral medulla). (C) P2X $\mathrm{X}_{5}$ immunoreactivity in the VLM. (D-F) There was strong immunoreaction of $\mathrm{P} 2 \mathrm{X}_{6}$ in the VLM. Note immunoreaction of cell processes and strongest reaction in neurones close to the ventral surface. Immunoreactivity was also seen in the nucleus ambiguus (amb, D). Scale bars $=250 \mu \mathrm{m}$ in $\mathrm{A}$ and $\mathrm{B}, 100 \mu \mathrm{m}$ in $\mathrm{D}-\mathrm{F}, 50 \mu \mathrm{m}$ in $\mathrm{C}$. 
vation, together with the fact that ATP had a greater excitatory effect during the expiratory phase than during the inspiratory phase of discharge of pre-inspiratory neurones, might account for the expiratory apnoea that was produced when $\mathrm{P} 2$ receptor agonists were microinjected grossly into the Bötzinger and pre-Bötzinger complexes in the present study.

Our observation that injections of suramin into the ventral medulla had no effect on baseline levels of ABP and HR confirms the results of others (Horiuchi et al., 1999). Whilst our unilateral injections of suramin were able to block the effects of ATP on respiratory drive they had no effect on baseline levels of respiratory activity. However, we have shown recently that bilateral microinjections of suramin into the VLM reduce resting phrenic nerve discharge suggesting that ATP has a role in determining the level of resting respiratory drive in the anaesthetised rat (Thomas et al., 1999).

The fact that prior microinjection of the $\mathrm{P} 2$ receptor antagonist suramin blocked the ATP-evoked effects on ventilatory drive suggests an involvement of P2 purinoceptors. This observation also makes it unlikely that the effects of ATP on respiratory drive can be attributed to its breakdown product adenosine which is known to have an inhibitory effect on respiration (Herlenius et al., 1997). Adenosine receptors are present in high density in this area of the brainstem and microinjection of adenosine into these regions can alter blood pressure and HR (Spyer and Thomas, 2000). However, the responses evoked by adenosine were considerably smaller than those evoked by ATP in the present study. Moreover, in a recent study we have shown that the $\mathrm{P} 1$ receptor antagonist 8-phenyltheophylline does not block the excitatory effects of ATP on neurones in the ventral medulla (Thomas and Spyer, 2000). Suramin has been shown to block ectonucleotidase activity, which may limit its effectiveness as an antagonist (Crack et al., 1994; Beukers et al., 1995). However, this does not alter our interpretations, as we did not observe a consistent or significant augmentation of the effects of ATP when suramin was microinjected into the VLM. Although non-specific effects of suramin have been reported in rat hippocampal neurones in culture (Nakazawa et al., 1995), suramin did not block responses to glutamate in the present study.

Our immunohistochemical data illustrate the presence of two suramin-sensitive $\mathrm{P} 2 \mathrm{X}$ receptor subtypes, $\mathrm{P} 2 \mathrm{X}_{1}$ and $\mathrm{P} 2 \mathrm{X}_{2}$, in the VLM. We also observed $\mathrm{P} 2 \mathrm{X}_{6}$ receptors in this region of the medulla, although this subtype is not sensitive to suramin. The $\mathrm{P} 2 \mathrm{X}_{6}$ subunit is unable to form functional homo-oligomeric assemblies but can co-assemble into hetero-oligomeric assemblies with many other $\mathrm{P} 2 \mathrm{X}$ subunits, including the $\mathrm{P} 2 \mathrm{X}_{1}$ and $\mathrm{P} 2 \mathrm{X}_{2}$ subtypes (Torres et al., 1999). Therefore we would suggest that various $\mathrm{P} 2 \mathrm{X}$ subunits form heteromeric receptors in the VLM, which could account for the functional responses we observed. In support for this, we have recently shown that co-expression of $\mathrm{P} 2 \mathrm{X}_{2}$ and $\mathrm{P} 2 \mathrm{X}_{6}$ subunits in Xenopus oocytes produces a functional heteromeric $\mathrm{P} 2 \mathrm{X}_{2 / 6}$ receptor that exhibits suramin sensitivity (King et al., 2000). We have shown recently that ATP-evoked excitation of inspiratory neurones underlies carbon dioxide-mediated excitation of respiratory activity (Thomas and Spyer, 2000). Our observation that $\mathrm{P} 2 \mathrm{X}_{2}$ reactivity was present in the VLM is therefore particularly significant, since this receptor subtype is known to be highly sensitive to changes in $\mathrm{pH}$ (King et al., 1996).

Our immunohistochemical demonstration that $\mathrm{P} 2 \mathrm{X}_{1}$, $\mathrm{P} 2 \mathrm{X}_{2}, \mathrm{P} 2 \mathrm{X}_{5}$ and $\mathrm{P} 2 \mathrm{X}_{6}$ receptor subtypes are present in the VLM is consistent with other studies that have looked for P2X receptors in the CNS (e.g. Yao et al., 2000). $P 2 X_{1}$ receptors have been recently shown to be present in the cerebellum and $\mathrm{P} 2 \mathrm{X}_{2}$ receptors in the hypothalamus of the rat (Loesch and Burnstock, 1998; Xiang et al., 1998). More specifically, a recent study by Kanjhan et al. (1999) reported moderate immunolabelling of $\mathrm{P} 2 \mathrm{X}_{2}$ subtypes and high levels of $\mathrm{P} 2 \mathrm{X}_{2}$ receptor mRNA in the VLM. RNA for $\mathrm{P}_{2} \mathrm{X}_{6}$ subunits has also been shown previously to be present in the paragiganticellular nucleus (Collo et al., 1996), consistent with our findings. That particular study also showed RNA for $\mathrm{P} 2 \mathrm{X}_{4}$ in this region and suggested that the $\mathrm{P} 2 \mathrm{X}_{4}$ and $\mathrm{P}^{2} \mathrm{X}_{6}$ subunits are the most heavily expressed in the brain (Collo et al., 1996). Consistent with this, our data indicate that the $\mathrm{P}_{2} \mathrm{X}_{6}$ subunit is the most prolific $\mathrm{P} 2 \mathrm{X}$ subunit in the ventral medulla. A recent study in the rat describes the presence of all six $\mathrm{P} 2 \mathrm{X}$ receptors in the VLM (Yao et al., 2000). In accordance with our data, that study indicated that levels of $\mathrm{P} 2 \mathrm{X}_{3}, \mathrm{P} 2 \mathrm{X}_{4}$ and $\mathrm{P} 2 \mathrm{X}_{5}$ were lower in the VLM than those for $\mathrm{P} 2 \mathrm{X}_{1}, \mathrm{P} 2 \mathrm{X}_{2}$ and $\mathrm{P}^{2} \mathrm{X}_{6}$ (Yao et al., 2000). However, we did not find any evidence for $\mathrm{P}_{2} \mathrm{X}_{3}$ and $\mathrm{P} 2 \mathrm{X}_{4}$ labelling in the VLM in this study. We can be sure that these antibodies were effective since we observed $\mathrm{P} 2 \mathrm{X}_{3}$ labelling in dorsal regions of the brainstem (e.g. nucleus tractus solitarius) and $\mathrm{P} 2 \mathrm{X}_{3}$ and $\mathrm{P}_{2} \mathrm{X}_{4}$ reactivity in very caudal regions of the ventral medulla and in the region of the nucleus ambiguus. These differences between labelling observed in the present study and that of Yao et al. (2000) are difficult to reconcile, but may be due to the use of antibodies from different sources which may have different sensitivities (Oglesby et al., 1999; Yao et al., 2000).

Whilst seven types of $\mathrm{P} 2 \mathrm{X}$ receptor proteins have been cloned to date (Ralevic and Burnstock, 1998), the P2X selectivity of $\alpha, \beta$-meATP indicates a possible involvement of $\mathrm{P} 2 \mathrm{X}_{1}$ and/or $\mathrm{P} 2 \mathrm{X}_{3}$ receptors. This is supported by our immunohistochemical data, which show that the $\mathrm{P} 2 \mathrm{X}_{1}$ subtype is localised within this region. This receptor is known to desensitise rapidly (Valera et al., 1994; Chen et al., 1995; Lewis et al., 1995; Collo et al., 1996), which is consistent with the pronounced and long-lasting desensitisation we observed upon repeated microinjection of $\alpha, \beta$-meATP. This contrasts with results obtained in the rabbit, where repeated injections of $\alpha, \beta$-meATP produced reproducible cardiovascular responses, without desensitisation (Horiuchi et al., 1999). This might reflect species differences in the $\mathrm{P} 2 \mathrm{X}$ receptor subtypes localised within the VLM or the formation of heteromultimers, which show different pharmacological profiles. In addition, an involvement of $\mathrm{G}$ protein-coupled $\mathrm{P} 2 \mathrm{Y}$ receptors for ATP is also possible and cannot be discounted. The fact that the responses to ATP upon repeated microin- 
jection were reproducible may be due to the rapid breakdown of ATP by ectonucleotidases such that there was minimal opportunity for desensitisation to occur. Differential actions at homomeric $\mathrm{P} 2 \mathrm{X}$ receptors could also account for the differential susceptibility to desensitisation of responses to ATP and $\alpha, \beta$-meATP.

There is evidence of an integration of inputs related to cardiovascular and respiratory activity within the VLM. However, several observations reduce the possibility that the respiratory changes evoked by ATP that we describe are secondary to reflexes evoked as a consequence of cardiovascular changes. Firstly, the inhibitory effects of ATP and $\alpha, \beta$-meATP on respiration often preceded any cardiovascular changes. Also the fact that suramin abolished the ATP-evoked apnoea, but did not reduce the hypertensive or tachycardic responses to higher doses of ATP in some cases, and that the respiratory and cardiovascular responses to $\alpha, \beta$-meATP desensitised with different temporal profiles might indicate independence of the cardiovascular and respiratory effects of ATP. However, we cannot discount the possibility that different $\mathrm{P} 2$ receptor subtypes are responsible for the respiratory and cardiovascular changes, which could also explain the latter results. In light of our previous electrophysiological data, however, we would suggest that ATP could modulate directly, and independently, the respiratory and cardiovascular pathways via actions within the VLM.

\section{CONCLUSION}

The results of this study indicate that activation of $\mathrm{P} 2 \mathrm{X}$ receptors in the VLM can exert pronounced, independent, effects on the respiratory and cardiovascular systems. Our data also suggest that ATP might have a role in the control of respiratory drive via an action on the respiratory network in this area of the brainstem. We have recently suggested that $\mathrm{pH}$-sensitive ATP receptors in this area of the medulla are involved in carbon dioxide-mediated increases in respiration (Thomas and Spyer, 2000). Further research is necessary, however, to determine whether $\mathrm{P} 2$ receptors in other regions of the brainstem are also involved in determining ventilatory drive during resting conditions and in situations of hypercapnia and hypoxia.

Acknowledgements-This work was supported by the British Heart Foundation, The Royal Society and Roche Bioscience, Palo Alto, CA, USA.

\section{REFERENCES}

Beukers, M.W., Kerkoff, C.J.M., Van Rhee, A.M., Ardanuy, U., Gurgel, C., Widjaja, H., Nickel, P., Ijzerman, A.P., Soudijn, W., 1995. Suramin analogues, divalent cations and ATP $\gamma \mathrm{S}$ as inhibitors of ecto-ATPase. Naunyn-Schmiedeberg's Arch. Pharmacol. 351, 523-528.

Chen, C.-C., Akopian, A.N., Sivilotti, L., Colquhoun, D., Burnstock, G., Wood, J.N., 1995. A P2X purinoceptor expressed by a subset of sensory neurons. Nature 377, 428-431.

Collo, G., North, R.A., Kawashima, E., Merlo-Pich, E., Neidhart, S., Suprenant, A., Buell, G., 1996. The cloning of P2X $(5)$ and P2X $(6)$ receptors and the distribution and properties of an extended family of ATP-gated ion channels. Neuroscience 16, $2495-2507$.

Crack, B.E., Beukers, M.W., McKechnie, K.C.W., Ijzerman, A.P., Leff, P., 1994. Pharmacological analysis of ecto-ATPase inhibition: evidence for combined enzyme inhibition and receptor antagonism in P2X-purinoceptor ligands. Br. J. Pharmacol. 113, $1432-1438$.

Day, T.A., Sibbald, J.R., Khanna, S., 1993. ATP mediates noradrenergic neuron input to supraoptic vasopressin cells. Brain Res. 607, 341-344.

Edwards, F.A., Gibb, A.J., Colquhoun, D., 1992. ATP receptor-mediated synaptic currents in the central nervous system. Nature 359, 144-147.

Fries, W., Zieglgansberger, W., 1974. A method to discriminate axonal from cell body activity and to analyse 'silent cells'. Exp. Brain Res. 21, 441445 .

Harboe, N., Ingild, A., 1973. Immunization, isolation of immunoglobins, estimation of titre. Scand. J. Immunol. 1 (Suppl.), 161-164.

Herlenius, E., Lagercrantz, H., Yamamoto, Y., 1997. Adenosine modulates inspiratory neurons and the respiratory pattern in the brainstem of neonatal rats. Pediatr. Res. 42, 46-53.

Horiuchi, J., Potts, P.D., Tagawa, T., Dampney, R.A.L., 1999. Effects of activation and blockade of P2X receptors in the ventrolateral medulla on arterial pressure and sympathetic activity. J. Auton. Nerv. Syst. 76, 118-126.

Jahr, C.E., Jessel, T.M., 1983. ATP excites a subpopulation of rat dorsal horn neurons. Nature 304, 730-733.

Kanjhan, R., Housley, G.D., Burton, L.D., Christie, D.L., Kippenberger, A., Thorne, P.R., Luo, L., Ryan, A.F., 1999. Distribution of the P2X receptor subunit of the ATP-gated ion channels in the rat central nervous system. J. Comp. Neurol. $28,11-32$.

King, B.F., Townsend-Nicholson, A., Wildman, S.S., Thomas, T., Spyer, K.M., Burnstock, G., 2000. Coexpression of rat P2X 2 and P2X 6 subunits alters the operational profile of the wildtype P2X2 receptor. J. Neurosci. 20, 4871-4877.

King, B.F., Ziganshina, L.E., Pintor, J., Burnstock, G., 1996. Full sensitivity of the P2X 2 purinoceptor to ATP revealed by changing extracellular pH. Br. J. Pharmacol. 117, 1371-1373.

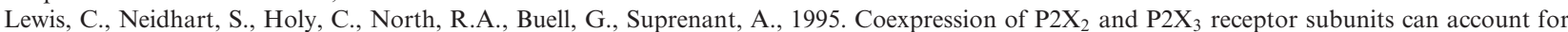
ATP-gated currents in sensory neurons. Nature 377, 432-435.

Llewellyn-Smith, I.J., Pilowsky, P., Minson, J.B., 1993. The tungstate-stabilized tetramethylbenzidine reaction for light and electron microscopic immunocytochemistry and for revealing biocytin-filled neurons. J. Neurosci. Methods 46, 27-40.

Llewellyn-Smith, I.J., Song, Z.M., Costa, M., Bredt, D.S., Snyder, S.H., 1992. Ultrastructural localization of nitric oxide synthase immunoreactivity in guinea-pig enteric neurons. Brain Res. 577, 337-342.

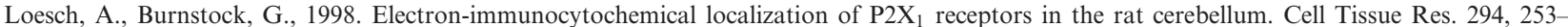
260 .

Nakazawa, K., Inoue, K., Ityo, K., Koizumi, S., Inoue, K., 1995. Inhibition by suramin and reactive blue 2 of GABA and glutamate receptor channels in rat hippocampal neurons. Naunyn-Schmiedeberg's Arch. Pharmacol. 351, 202-208.

Oglesby, I.B., Lachnit, W.G., Burnstock, G., Ford, A.P.D.W., 1999. Subunit specificity of polyclonal antisera to the carboxy terminal regions of $\mathrm{P} 2 \mathrm{X}$ receptors, $\mathrm{P} 2 \mathrm{X}_{1}$ through $\mathrm{P} 2 \mathrm{X}_{7}$. Drug Dev. Res. 47, 189-195.

Paxinos, G., Watson, C., 1998. The Rat Brain in Stereotaxic Co-ordinates. Academic, London. 
Phillis, J.W., Scislo, T.J., O’Leary, D.S., 1997. Purines and the nucleus tractus solitarius: effects on cardiovascular and respiratory function. Clin. Exp. Pharmacol. Physiol. 24, 738-742.

Ralevic, V., Burnstock, G., 1998. Receptors for purines and pyrimidines. Pharmacol. Rev. 50, 413-492.

Ralevic, V., Thomas, T., Burnstock, G., Spyer, K.M., 1999. Characterization of P2 receptors modulating neural activity in rat rostral ventrolateral medulla. Neuroscience 94, 867-878.

Ralevic, V., Thomas, T., Spyer, K.M., 1998. Effects of P2 purine receptor agonists microinjected into the rostral ventrolateral medulla on the cardiovascular and respiratory systems of the anaesthetised rat. J. Physiol. 509P, 127P.

Richter, D.W., 1996. Neural regulation of respiration: rhythmnogenesis and afferent control. In: Greger, R., Windhorst, U. (Eds.), Comprehensive Human Physiology. Springer-Verlag, Berlin, pp. 2079-2095.

Spyer, K.M., Thomas, T., 2000. A role for adenosine in modulating cardio-respiratory responses: A mini-review. Brain Res. Bull. 53, 121-124.

Sun, M.-K., Wahlestedt, C., Reis, D.J., 1992. Action of externally applied ATP on reticulospinal vasomotor neurons. Eur. J. Pharmacol. 224, 9396.

Sun, Q.-J., Goodchild, A.K., Chalmers, J.P., Pilowsky, P., 1998. The pre-Bötzinger complex and phase spanning neurons in the adult rat. Brain Res. 809, 204-213.

Thomas, T., Ralevic, V., Bardini, M., Burnstock, G., Spyer, K.M., 2000. Evidence for involvement of purinergic signalling in control of respiration. J. Physiol. 526P, 136P.

Thomas, T., Ralevic, V., Gadd, C.A., Spyer, K.M., 1999. Central $\mathrm{CO}_{2}$ chemoreception: a mechanism involving P2 purinoceptors localized in the ventrolateral medulla of the anaesthetised rat. J. Physiol. 517.3, 899-905.

Thomas, T., Spyer, K.M., 1996. The role of adenosine receptors in the rostral ventrolateral medulla in the cardiovascular response to defence area stimulation on the rat. Exp. Physiol. 81, 67-77.

Thomas, T., Spyer, K.M., 2000. ATP as a mediator of mammalian central $\mathrm{CO}_{2}$ chemoreception. J. Physiol. $523,441-447$.

Torres, G.E., Egan, T.M., Voigt, M.M., 1999. Hetero-oligomeric assembly of P2X receptor subunits. J. Biol. Chem. 274, 6653-6659.

Valera, S., Hussy, N., Evans, R.J., Adami, N., North, R.A., Suprenant, A., Buell, G.N., 1994. A new class of ligand-gated ion channel defined by a P2X receptor for extracellular ATP. Nature 371, 516-519.

Xiang, Z., Bo, X., Oglesby, I., Ford, A., Burnstock, G., 1998. Localization of ATP-gated P2X 2 receptor immunoreactivity in the rat hypothalamus. Brain Res. 813, 390-397.

Yao, S.T., Barden, J.A., Finkelstein, D.I., Bennett, M.R., Lawrence, A.J., 2000. Comparative study on the distribution patterns of P2X1-P2X6 receptor immunoreactivity in the brainstem of the rat and the common marmoset (Callithrix jacchus): Association with catecholamine cell groups. J. Comp. Neurol. 427, 485-507. 